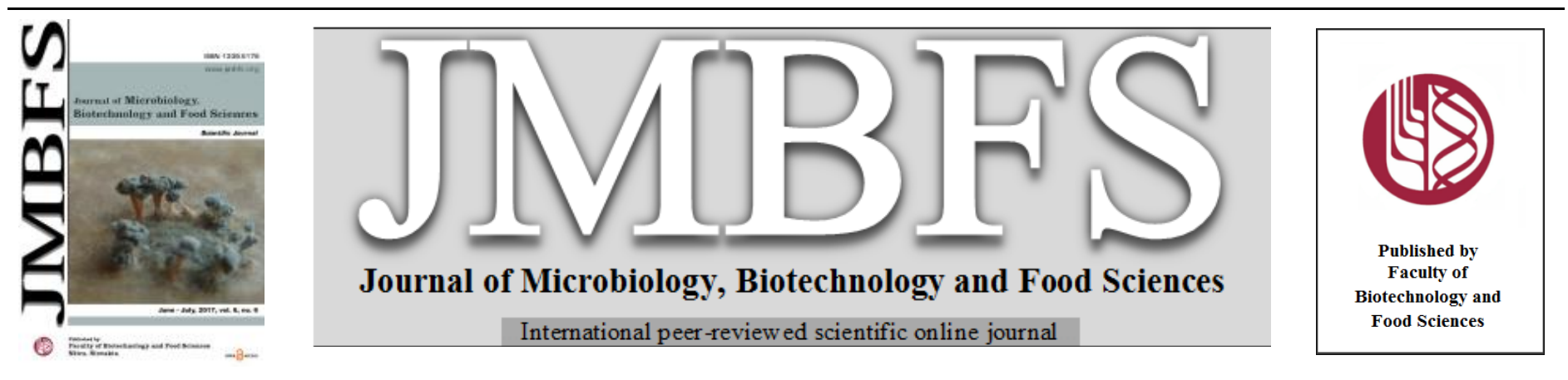

\title{
POTENTIAL OF SELECTED SSR MARKERS FOR IDENTIFICATION OF MALTING BARLEY GENOTYPES
}

\section{Marián Tomka*, Dana Urminská, Milan Chňapek, Zdenka Gálová}

\section{Address(es):}

Slovak University of Agriculture in Nitra, Faculty of Biotechnology and Food Sciences, Department of Biochemistry and Biotechnology, Tr. A. Hlinku 2, 949 76, Nitra, Slovak Republic.

*Corresponding author: ing.mariantomka@gmail.com

\section{ARTICLE INFO}

Received 15. 2. 2017

Revised 20. 4. 2017

Accepted 17. 5. 2017

Published 1. 6. 2017

Regular article OPEN 2 ACCESS

\begin{abstract}
Cereals are main part of human nutrition and strategic resources. Thousands of barley varieties are used in food industry and especially for the production of malt in the brewing industry. In the present study, we were focused on utilization of SSR markers for differentiation and characterization of different barley genotypes. Barley collection was analyzed by 4 pure and 1 compound markers. Using STMS method we have revealed significant polymorphism. A total of 27 alleles were detected among 24 varieties with an average of 5.4 alleles per locus. Average values for index of diversity (DI), polymorphic information content (PIC) were $0.767,0.756$ respectively. The highest level of polymorphism was detected with SSR marker Bmag 0222 (7 alleles) which also revealed one heterozygous variety. Dendrogram was created by hierarchic cluster analysis using UPGMA algorithm on the basis of detected alleles. Analyzed genotypes were divided into three clusters so it can be used to study genetic relations among collection of analyzed barley varieties.
\end{abstract}

Keywords: Barley, Genetic diversity, Simple sequence repeat (SSR), DNA marker

\section{INTRODUCTION}

Cereals are grown across the globe for several thousand years, and after all these years have been subjected to various exogenous and endogenous factors which have formed their respective genomes. Barley (Hordeum vulgare, L.) is economically important crops mainly for food production and malting, but the value is increased due to use as a functional food with a variety of health benefits Hua et al. (2015). In order to increase the nutritional quality of grain, barley crop passed through the targeted selection and hybridization. The long process of barley breeding has resulted in increasing diversity of barley varieties Ivandic $\boldsymbol{e}$ al. (2003). Growers can select the best variety according to specific climate and end use of this crop such as human consumption, malt in brewing and distilling industry or animal feeding Ferreira et al. (2016). At present approximately hundred varieties of barley genotypes are registered in Slovakia, of which 20\% have domestic origin. Wild barleys (Hordeum spontaneum) can be used as donors of important genes that could be used for improvement of different barley parameters Shakhatreh et al. (2016). Molecular markers such as SSR, SNP, STS Kojima et al. (2007), Thormann et al. (2016) or DArT Lamaraet al. (2013) are often used for genotype identification and characterization and thus may provide more accurate genome assessment Yadav et al. (2015). Association mapping is a powerful tool in improving barley breeding via precise identification of markers significantly associated with important traits, which is vitally important for marker-assisted breeding Abou-Elwafa (2016), Elakhdar et al. (2016). Molecular markers are very useful for mapping and tagging the loci affecting malting quality Han $\boldsymbol{e t}$ al. (1997) and largely fulfill most of the user requirements Groven and Sharma (2016). Using molecular markers to select for specific chromosome regions with potential positive yield contributions enhanced the breeding success for high yield while maintaining traditional malting quality Schmierer et al. (2005).

The aim of this study was to analyze genetic diversity among the set of 24 barley genotypes using 5 SSR markers and to evaluate their ability to identify malting barley genotypes.

\section{MATERIAL AND METHODS}

Collection of 24 barley genotypes contained 8 winter form (Tiffany, Monaco, Cedeco, Premuda, Graciosa, Barcelona, Metaxa, Heidi) and 16 spring form (Malz, Kangoo, Overture, Signora, Nadir, Laudis 550, Karmel, Antigone, Troon, Prodeum, Valis, Exalis, Kumran, Kompakt, Novum and Madonna) barleys. Some of these genotypes are commonly used in brewing industry. DNA was isolated from dry whole grain according to the methodology for a commercial kit GeneJET Genomic DNA Purification Plant Mini Kit from the Thermo Fisher Company.

Microsatellite analyses were carried out in $25 \mu 1$ volume using Biorad C 1000 Thermocycler. As primers we used specific oligonucleotide sequences 18-23 bp, described by Ramsay et al. (2000). The amplification conditions for each microsatellite marker were set according to Ramsay et al. (2000) and Varshney et al. (2007). Primers (Table 1) were selected on the basis of our previous research Tomka et al. (2013), on the basis of best values for DI and PIC due to ability of differentiation. 
Table 1 List of used SSR markers

\begin{tabular}{cccc}
\hline Markers & Chromosome & $\begin{array}{c}\text { Primer sequence } \\
\left(\mathbf{5}^{\prime} \mathbf{- 3}^{\prime}\right)\end{array}$ & Repetition \\
\hline Bmac 0040 & $6 \mathrm{H}$ & $\begin{array}{c}\text { AGCCCGATCAGATTACG } \\
\text { TTCTCCCTTTGGTCCTTG }\end{array}$ & $(\mathrm{AC})_{20}$ \\
\hline Bmac 0134 & $2 \mathrm{H}$ & $\begin{array}{c}\text { CCAACTGAGTCGATCTCG } \\
\text { CTTCGTTGCTTCTCTACCTT }\end{array}$ & $(\mathrm{AC})_{28}$ \\
\hline Bmag 0125 & $2 \mathrm{H}$ & $\begin{array}{c}\text { AATTAGCGAGAACAAAATCAC } \\
\text { AGATAACGATGCACCACC }\end{array}$ & $(\mathrm{AG})_{19}$ \\
\hline Bmag 0211 & $1 \mathrm{H}$ & $\begin{array}{c}\text { ATTCATCGATCTTGTATTAGTCC } \\
\text { ACATCATGTCGATCAAAGC }\end{array}$ & $(\mathrm{CT})_{16}$ \\
\hline Bmag 0222 & $5 \mathrm{H}$ & $\begin{array}{c}\text { ATGCTACTCTGGAGTGGAGTA } \\
\text { GACCTTCAACTTTGCCTTATA }\end{array}$ & $(\mathrm{AC})_{9}(\mathrm{AG})_{17}$ \\
\hline
\end{tabular}

Amplified alleles were separated in the $6 \%$ polyacrylamide gels denatured with urea. Preparation of the gel solution to a total volume of $100 \mathrm{ml}: 18.5 \mathrm{ml} 40 \%$ acrylamid / bisacrylamid in ratio 19:1; $5 \mathrm{ml} 10 \mathrm{x}$ TBE (107.8 g Tris-base, $7.44 \mathrm{~g}$ EDTA and $55 \mathrm{~g} \mathrm{H}_{3} \mathrm{BO}_{3}$ in 1L solution, $\mathrm{pH} 8.3$ ); $20 \mathrm{ml}$ redistilled water; $55.82 \mathrm{ml}$ $66.3 \%$ urea; $180 \mu 1$ TEMED and $500 \mu 110 \%$ APS solution.

The separation of amplified alleles was conducted at OWLTM electrophoresis unit at maximum current $90 \mathrm{~mA}$ in a buffer system 1 x TBE for 3-4 hours, depending on the expected size of fragments. After electrophoretic separation of DNA, bands were visualized by silver staining followed Benbouza et al. (2006): 5 minutes in fixative solution (10\% ethanol; $0.5 \%$ acetic acid),

6-7 minutes in a dye solution $\left(1.5 \mathrm{~g} \mathrm{AgNO}_{3}, 1.5 \mathrm{ml} 37 \% \mathrm{H}_{2} \mathrm{CO}, \mathrm{H}_{2} \mathrm{O}\right.$ to 1000 $\mathrm{ml})$,

1 second washing in ultrapure water,

3-5 minutes in develop solution ( $15 \mathrm{~g} \mathrm{NaOH}, 2 \mathrm{ml} 37 \% \mathrm{H}_{2} \mathrm{CO}, \mathrm{H}_{2} \mathrm{O}$ to $1000 \mathrm{ml}$ ), 2 minutes in fixative solution (10\% ethanol; $0.5 \%$ acetic acid).

The PCR products separated in polyacrylamide gels were scanned using ChemiDoc Imaging System followed by evaluation using the GelAnalyzer 2010 software (Lazar 2010). On the basis of allele frequency diversity index (DI) (Weir, 1990) and polymorphic information content (PIC) (Weber, 1990) were calculated.

\section{RESULTS AND DISCUSSION}

Number of alleles per locus is an important indicator of genetic diversity. For some authors it is the only and main parameter for study of genetic relations. Kalinowsky (2002) statistically confirmed that it is not required to examine highly polymorphic loci or large numbers of loci. The only requirement is that a sufficient number of alleles have been detected. Overall, we have identified 27 alleles at five loci which were located on chromosomes $1 \mathrm{H}, 2 \mathrm{H}, 5 \mathrm{H}$ and $6 \mathrm{H}$ Number of allele per locus varied from 4 (Bmag 0211) to 7 (Bmag 0222) with average value of 5.4. Frequencies of detected alleles ranged from $4.0 \%$ to $50.0 \%$ (figure 1). Shakhatreh et al. (2016) analyzed comparable collection of cultivated barleys (27 genotypes) but have used 11 markers and therefore identified more alleles (95) with an average 8.6 allele per locus. Yadav $\boldsymbol{e t}$ al. (2015) used even more markers (47 SSR's) but his collection of barley contained just 10 barley cultivars. Number of alleles per locus varied from 2 to 7 with an average 3.52 alleles per locus. Using markers Bmac 0040 and Bmag 0222 they have identified 5 and 6 alleles respectively, which is very close to our results. Similar results obtained Nandh and Singh (2014) who analyzed 27 wild and 20 cultivated barley accessions and identified 5 alleles at loci Bmag 0125 and also Bmag 0211 in cultivated barley collection. Khodayari et al. (2014) analyzed 40 wild barley genotypes and have identified from 1 to 17 alleles but SSR marker Bmag 0125 amplified only 4 alleles. Hua et $\boldsymbol{a l}$. (2015) identified 204 alleles with mean value of 5.83 in collection of 277 colored barley varieties. Due to very large collection of genotypes, number of alleles detected in the same loci were much higher Bmac 0040 (42 alleles), Bmag 0134 (35 alleles), Bmag 0222 (19 alleles). Ferreira et al. (2016) analyzed 64 Brazilian barley genotypes and in 34 different loci they have identified from 1 up to 18 alleles. Using marker Bmag 0211 they have identified 6 alleles but in the case of marker Bmag 0125 number of detected alleles (10) was double compared to our results.
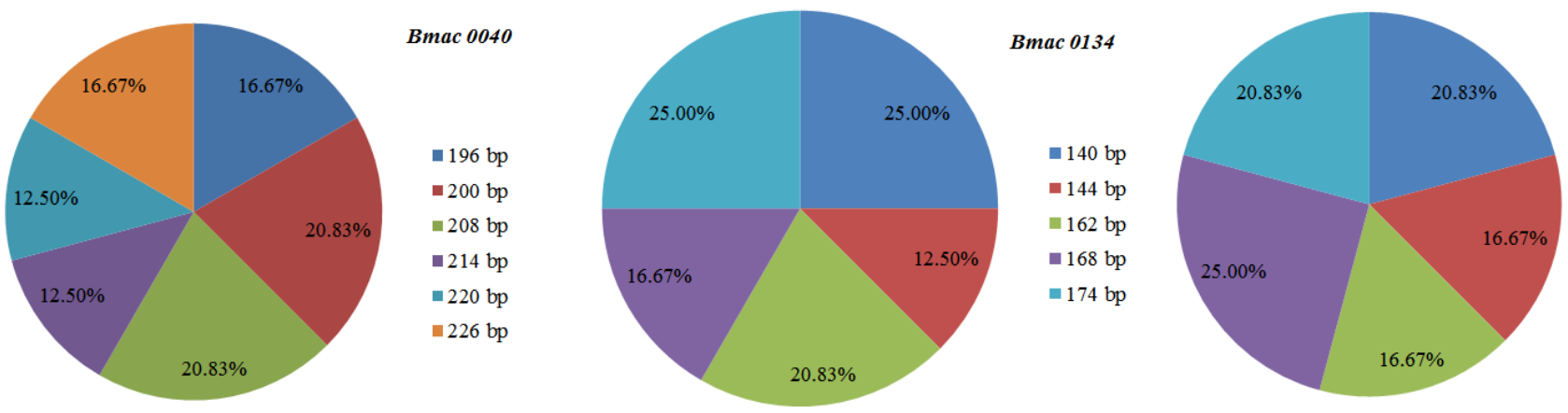

Bmag 0125
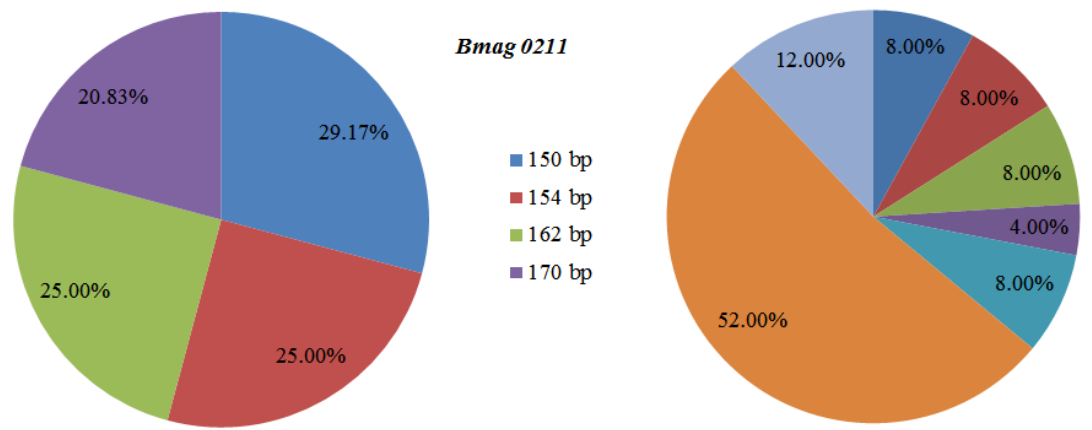

Bmag 0222

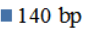

- $144 \mathrm{bp}$

$162 \mathrm{bp}$

$168 \mathrm{bp}$

$170 \mathrm{bp}$

$174 \mathrm{bp}$

$178 \mathrm{bp}$

Figure 1 Preview of detected alleles in 5 SSR loci and their frequencies

Calculated indexes of DI, PIC are used to evaluate the level of polymorphism in analyzed collections of different species. The higher value for these indexes is calculated the better identification they provide (table 2). PIC values are used as a measure of a marker's usefulness for linkage analysis. Values of index diversity for our SSR markers were calculated and varied from 0.688 to 0.826 with a mean value of 0.767 . For the next index (PIC) values ranged from 0.677 to 0.817 with an average value of 0.756 . These values indicate that these markers are able to detect high level of polymorphism because markers with DI and PIC values over 0.6 are considered as useful tool for genotype differentiation. Nandh and Singh (2014) in comparable collection of 20 cultivated barleys estimated average value of diversity index of 0.729 , what is very close to our result. Polymorphic information content indexes for SSR markers Bmac 0134 (0.835), Bmag 0125 (0.685) and Bmag 0211 (0.760) were comparable to our values. Khodayari et al. (2014) computed values for PIC index from 0.304 to 0.913 with mean value of 
0.711. Also Lamara et al. (2013) calculated similar average PIC index (0.690). Other authors Yadav et al. (2015) and Hua et al. (2015) acquired lower mean values of PIC 0.551 and 0.549 but this was affected with some SSR markers with low level of polymorphism and thus lower value of PIC 0.286 and 0.407 .

Table 2Characteristics ofindividual SSR markers

\begin{tabular}{ccccc}
\hline Markers & Numberofalleles & $\begin{array}{c}\text { Allele } \\
\text { size }\end{array}$ & DI & PIC \\
\hline Bmac 0040 & 6 & $196-226 \mathrm{bp}$ & 0.826 & 0.817 \\
\hline Bmac 0134 & 5 & $140-174 \mathrm{bp}$ & 0.788 & 0.779 \\
\hline Bmag 0125 & 5 & $128-148 \mathrm{bp}$ & 0.795 & 0.782 \\
\hline Bmag 0211 & 4 & $150-170 \mathrm{bp}$ & 0.747 & 0.723 \\
\hline Bmag 0222 & 7 & $140-178 \mathrm{bp}$ & 0.688 & 0.677 \\
\hline
\end{tabular}

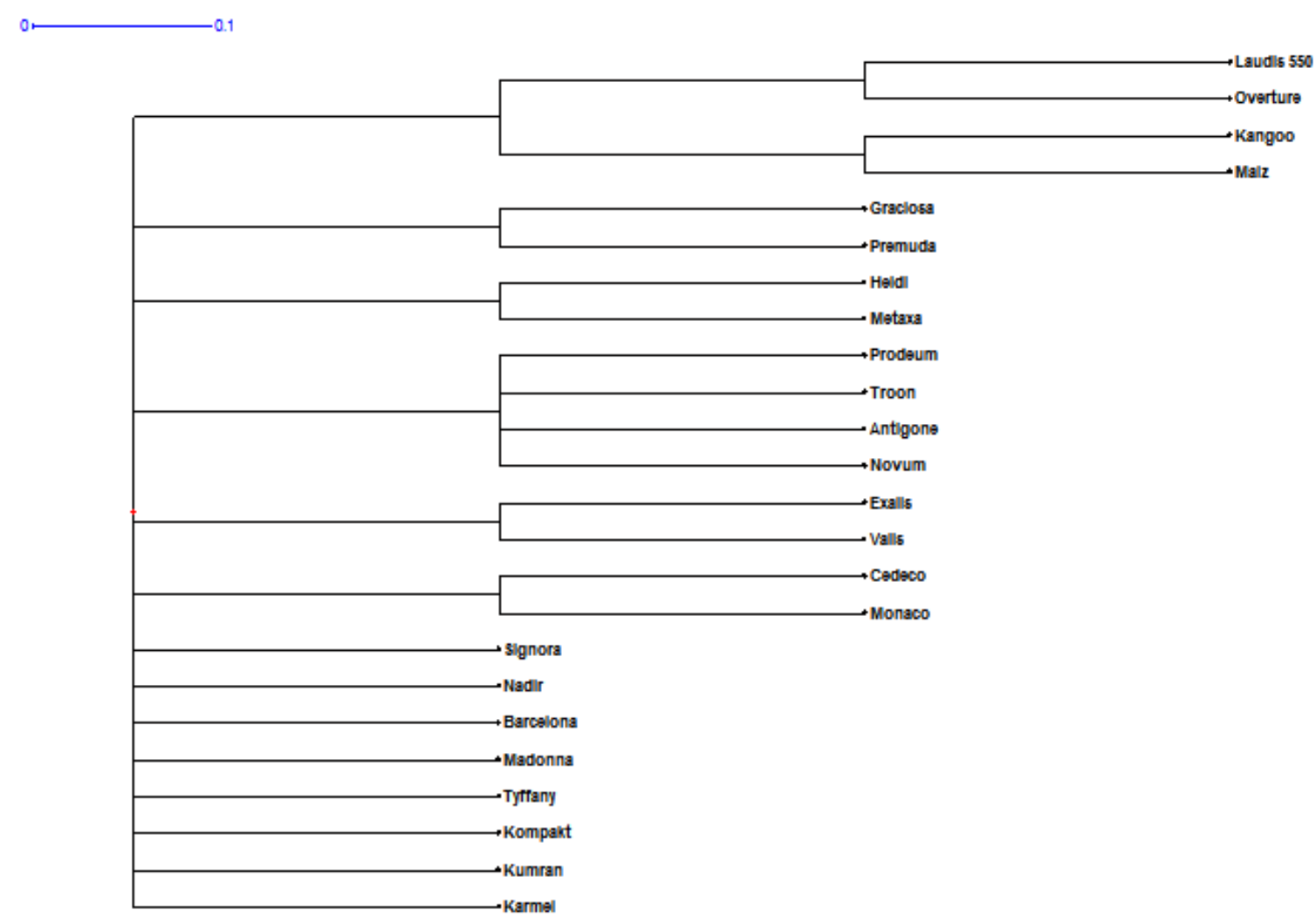

Figure 2 Dendrogram of 24 barley genotypes on the basis of 5 SRR markers

\section{CONCLUSION}

Molecular markers have been used many years for different applications mainly genotype and gene identification and genome mapping. According to obtained results, they are still very popular tool which helps growers and breeders to select the elite genotypes for their needs. Our results demonstrate the effectiveness of used SSR marker collection for differentiation of barley varieties and proved that SSR markers from our collection are still used worldwide for different applications. Comparable results with other authors confirmed potential of analyzed SSR markers for barley genotypes identification and characterization. Created dendrogram revealed relations between barley varieties and showed that this collection of SSR markers have some potential to differentiate malting barley cultivars.

Acknowledgments: This work was supported by project ITMS 26220120054 and project KEGA 020SPU-4/2016.

\section{REFERENCES}

Abou-Elwafa, S. F. (2016). Association mapping for yield and yield-contributing traits in barley under drought conditions with genome-based SSR markers. $\begin{array}{llll}\text { Comptes rendus } & \text { biologies, } & 339(5), & 153-162 .\end{array}$ http://dx.doi.org/10.1016/j.crvi.2016.03.001

Benbouza, H., Jacquemin, J. M., Baudoin, J. P., \&Mergeai, G. (2006) Optimization of a reliable, fast, cheap and sensitive silver staining method to detect SSR markers in polyacrylamide gels. Biotechnologie, agronomie, société et environnement, 10(2), 77-81.

\begin{tabular}{lllll} 
Average & 5.4 & - & $\mathbf{0 . 7 6 7}$ & $\mathbf{0 . 7 5 6}$ \\
\hline egend: DI- diversity index, & PIC- polymorphic information content, & &
\end{tabular}

DNA fragments amplified by 5 SSR markers were evaluated and on the basis of their presence or absence binary matrix was created. In the next step on the basis of this matrix dendrogram (figure 2) was created which revealed genetic relations between barley genotypes. We have successfully differentiated all 24 genotypes but we have failed to separate spring and winter forms as Pillen $\boldsymbol{e t}$ al. (2000) in their study but they have used almost 40 markers. We can get better results by choosing different collection of SSR markers or by using more markers. On the other hand our set of markers showed some potential to differentiate malting barleys when 4 of them created own cluster, moreover genotypes Laudis 550, Overture and Kangoo are considered as varieties with premium malting quality, what is claimed by producers. 
Khodayari, H., Saeidi, H., Akhavan, A., Pourkheirandish, M., \& Komatsuda, T. (2014). Microsatellite analysis of genetic diversity of wild barley (Hordeum vulgare subsp. spontaneum) using different sampling methods in Iran. Iranian Journal of Botany, 20, 41-50.

Kojima, L., Yang, F., Donovan, L. M., \&Dawson, K. J. (2007). QTL analysis for some quantitative traits in Hulless barley. Journal of Plant Genetics, 20, 71-83.

Lamara, M., Zhang, L. Y., Marchand, S., Tinker, N. A., \& Belzile, F. (2013).

Comparative analysis of genetic diversity in Canadian barley assessed by SSR DarT, and pedigree data. Genome, 56(6), 351-358. http://dx.doi.org/10.1139/gen2013-0048

Lazar, I. (2010). GelAnalyzer software. Avalaible on: http://www.gelanalyzer.com

Nandha, P. S., \&Singh, J. (2014). Comparative assessment of genetic diversity between wild and cultivated barley using SSR and EST-SSR markers. Plant breeding, 133(1), 28-35. http://dx.doi.org/10.1111/pbr.12118

Pillen, K., Binder, A., Kreuzkam, B., Ramsay, L., Waugh, R., Förster, J., \& Leon, J. (2000). Mapping new EMBL-derived barley microsatellites and their use in differentiating German barley cultivars. Theoretical and Applied Genetics, 101(4), 652-660. http://dx.doi.org/10.1007/s001220051527

Ramsay, L., Macaulay, M., Ivanissevich, S. D., MacLean, K., Cardle, L., Fuller, J., Edwards, K. J., Tuvesson, S., Morgante, M., Massari, A., Maestri, E., Marmiroli, N., Sjakste, T., Ganal, M., Powell, W., \& Waugh, R. (2000). A simple sequence repeat-based linkage map of barley. Genetics, 156 (4), $1997-2005$. Schmierer, D. A., Kandemir, N., Kudrna, D. A., Jones, B. L., Ullrich, S. E., \&Kleinhofs, A. (2005). Molecular marker-assisted selection for enhanced yield in malting barley. Molecular Breeding, 14(4), 463-473. http://dx.doi.org/10.1007/s11032-004-0903-1

Shakhatreh, Y., Baum, M., Haddad, N., Alrababah, M., \& Ceccarelli, S. (2016) Assessment of genetic diversity among Jordanian wild barley (Hordeum spontaneum) genotypes revealed by SSR markers. Genetic Resources and Crop Evolution, 63(5), 813-822. http://dx.doi.org/10.1007/s10722-015-0285-8

Thormann, I., Reeves, P., Reilley, A., Engels, J. M., Lohwasser, U., Börner, A.,

Pillen, K., \& Richards, C. M. (2016). Geography of Genetic Structure in Barley Wild Relative Hordeum vulgare subsp. spontaneum in Jordan. PloSone, 11(8), http://dx.doi.org/10.1371/journal.pone.0160745

Tomka, M., Chnapek, M., Balážová, Z., \& Gálová, Z. (2013). Differentiation Of Barley Genotypes Based On DNA Polymorphism. The Journal of Microbiology, Biotechnology and Food Sciences, 2, 1677-1684.

Varshney, R.K., Marcel, T.C., Ramsay, L., Russell, J., Röder, M.S., Stein, N., Waugh, R., Langridge, P., Niks, R.E., \& Graner, A. (2007). A high density barley microsatellite consensus map with 775 SSR loci. Theoretical and Applied Genetics, 114(6), 1091-1103. http://dx.doi.org/10.1007/s00122-007-0503-7

Weber, J. L. (1990). Informativeness of human (dC-dA) n·(dG-dT) n polymorphisms. Genomics, 7(4), 524-530.

Weir, B. S. (1990). Genetic data analysis. Methods for discrete population genetic data. Sinauer Associates, Inc. Publishers.

Yadav, S. K., Singh, A. K., \& Malik, R. (2015). Genetic diversity analysis based on morphological traits and microsatellite markers in barley (Hordeum vulgare). The Indian Journal of Agricultural Sciences, 85(10), 37-44. 